\title{
Propuesta FEMINISTA PARA ACCEDER AL DERECHO AL NOMBRE EN CHIHUAHUA
}

GABRIELA OROZCO LÓPEZ1

\section{RESUMEN}

11

n este trabajo se proponen acciones para que la mujer participe en la conformación del nombre familiar, en los actos de registro de nacimiento y el reconocimiento de hijos e hijas, previendo el acuerdo de los progenitores respecto a la prelación de los apellidos que corresponderán al hijo. Se abordan los prejuicios en contra de la mujer y el hijo de la madre soltera, como interferencia para que la mujer acceda al derecho al nombre. La responsabilidad que deriva del acceso al nombre es esencial para fomentar las prácticas de paridad de género.

Palabras clave: derecho al nombre, feminismo, Chihuahua.

1 Cursa el doctorado en Derecho del Instituto de Investigaciones Jurídicas de la Universidad Nacional Autónoma de México. 


\begin{abstract}
In this paper, actions are proposed so that the woman participates in the conformation of the family name, in the acts of birth registration and the recognition of children, anticipating the agreement of the parents about the priority of the surnames that will correspond to the child. Prejudices against women and the unmarried mother's child are addressed as interference for women to access the right to a name. The responsibility derived from the access to the name is essential to promote the practices of gender parity.
\end{abstract}

Key words: right to a name, feminism, Chihuahua.

\title{
I. INTRODUCCIÓN
}

El nombre son las palabras que se usan para individualizar e identificar a una persona, cuya representación es el apelativo conformado por el nombre(s) propio(s) y apellido(s). El autor argentino Juan M. Semon dice que, la denominación de una persona le da su lugar fijo y su importancia en el mundo de los demás sujetos y objetos. Una persona sin nombre es como una obra literaria o científica sin título ni referencias de su autor. Es un ser viviente, sin derechos y sin responsabilidad individual por sus actos (Semon, 1946).

Este texto nos da la pauta para decir, el nombre de las personas al ser lenguaje tiene un marco filosófico, el cual comprende la idea existencialista de nombrar a quien se desea contar y distinguir; por el contrario, se niega un nombre a las personas que se pretenden cosificar y silenciar, a ellos se les generaliza mediante categorías, números y claves. En la antigüedad no se usaba un nombre individual para las mujeres, tampoco para las y los niños, ni para las y los esclavos. En aquel tiempo se identificaban a las personas con el nombre del pater familia ${ }^{2}$ al que pertenecían

2 Luces Gil, Francisco, El nombre civil de las personas naturales en el ordenamiento jurídico español, pp. 22 y 23. “... en el nombre Publio Cornelio Scipión Africano, Publio 
(Luces Gil, 1978: 22-23), aunando cierta denominación particular a fin de distinguir las posesiones. En la edad media, se utilizaba el título del Señor de la tierra para la formación de los nombres propios y apellidos. En tiempos modernos, se cometieron irreparables violaciones a los derechos humanos, empezando por borrar el nombre de las víctimas, en este sentido se cita el testimonio de un prisionero del campo de concentración en Polonia en 1942: los que ingresábamos éramos registrados y recibíamos un número de identificación que nos tatuaban en el antebrazo izquierdo, como animales. El mío fue el 73 670, lo que quiere decir que llegué entre los primeros 100 000. La cifra quedaba en lugar del nombre y del apellido, porque no teníamos derecho a mencionarlos (Conapred, 2007). En la actualidad, las personas víctimas de trata o en condición de calle y los inmigrantes pierden el nombre (si lo tuvieron) y, con ello, el medio de ser individualizados e identificados.

Por lo que respecta a la situación de la mujer, a ella la ley no le permite participar en la conformación del nombre familiar, ya que las hijas e hijos deben registrarse con el apellido paterno del padre, en primer lugar, seguido del apellido paterno de la madre, en segundo lugar. El nombre como institución establece relaciones de poder entre los miembros de la familia y la sociedad. En este sentido, la Suprema Corte de Justicia de la Nación (SCJN), en la sentencia del amparo en revisión 208/2016 del 19 de octubre de 2016, destacó: históricamente el mantenimiento o prevalencia de determinados apellidos ha pretendido perpetuar las relaciones de poder. ${ }^{3}$ La facultad para asignar nombres y priorizar apellidos, otorga a su titular una posición jerárquica superior en la familia y en la sociedad.

En cuanto al nombre de la mujer casada, por una parte, la legislación mexicana no lo regula, pero por otra, la Suprema Corte

era el praenomen, Cornelio el nomen, Scipión, el cognomen y el Africano, el agnomen; mención honorífica que recordaba las victorias de este general romano en África. Pero estos nombres graves y pomposos estaban reservados para los varones romanos. Las mujeres se designaban solo por el nomen en femenino (Tulia, Julia, Cornelia). Las mujeres casadas, como consecuencia de la in manum conventium agregaban el nombre de su marido en genitivo (por ejemplo, Tulia Metelli)".

3 Sentencia del 19 de octubre de 2016, primera sala, amparo en revisión, expediente 208/2016, ponente ministro Arturo Zaldívar Lelo de Larrea. 
de Justicia reconoció que existe una práctica social en México, (SCJN, 2012), consistente en que la mujer al contraer matrimonio, agregue los apellidos de su esposo a los propios. En el mismo sentido, la tesis jurisprudencial, Mujer casada, nombre de la... (SCJN, 1985) refiere que no puede desconocerse como uso social que las mujeres, al contraer matrimonio, agreguen a su nombre la preposición "de", seguida del primer apellido de su esposo. Sin embargo, el genitivo "de" textualmente expresa que la mujer pertenece al esposo.

La falta de participación de la mujer en el nombre familiar, así como la inclusión de los apellidos del esposo a los propios o anexar el genitivo "de", es una característica de invisibilidad social de la mujer mexicana y chihuahuense.

En el desarrollo del presente trabajo se abordarán las siguientes preguntas: ¿En el estado de Chihuahua se promueve, respeta, protege y garantiza el derecho humano al nombre para la mujer? ¿La participación de la mujer en la integración del nombre familiar pueden mitigar el patriarcado avasallante y normalizado en el estado de Chihuahua?

Para formular estas preguntas se advirtieron dos hechos, el primero es jurídico y el segundo es relativo a la convivencia actual de la sociedad chihuahuense urbana. ${ }^{4}$ Estos son:

i) El derecho al nombre es un derecho humano. Aunque la Constitución Política del Estado de Chihuahua no menciona expresamente el derecho al nombre, se concluye que en México, así como en los países latinoamericanos obligados convencionalmente, el nombre tiene el rango de derecho humano, ello de conformidad con el artículo 29, segundo párrafo, de la Constitución Política de los Estados Unidos Mexicanos, y los artículos 18 y 27 de la Convención Americana sobre Derechos Humanos.

ii) En la convivencia familiar, social y laboral de la sociedad chihuahuense se encuentran rasgos de la cultura del patriarca-

4 En este trabajo no se abordará la formación de nombres y la paridad de género en la cultura de los grupos indígenas de la entidad. 
do, el cual fue normalizado y en consecuencia es inadvertido; de aquí la aceptación por parte inclusive de la misma mujer, el varón y gobierno, que sea la primera la encargada de las tareas inherentes al hogar y al cuidado de la familia, en especial de los más vulnerables: las niñas, niños y adultos mayores; ello, por el hecho de nacer mujer. La vinculación que se hace de la mujer con las tareas domésticas y de cuidado, es enmarcada en la historia nacional, por ejemplo, el Código Civil Federal de 1928 (Reformado en 1964) decía que: Artículo 163. La mujer debe vivir al lado de su marido. 168. Estará a cargo de la mujer la dirección y cuidado de los trabajos del hogar. 169. La mujer podrá desempeñar un empleo, ejercer una profesión, industria, oficio o comercio, cuando ello no perjudique a la misión que le impone el artículo anterior. 170. El marido podrá oponerse a que la mujer se dedique a las actividades a que se refiere el artículo anterior, siempre que subvenga a todas las necesidades del hogar y funde la oposición en causas graves y fundadas.

Paradójicamente, también por el hecho de nacer mujer la ley niega a ella la capacidad para representar a su familia. Así, el artículo 60 del Código Civil del Estado de Chihuahua, no prevé la posibilidad de que un descendiente sea nombrado y registrado con el apellido materno, en primer lugar, seguido del apellido paterno. Esta injusticia se remonta a la antigüedad: para los griegos (igual que para los chihuahuenses) la mujer no podía tener el rango de Señora, en otras palabras, el título de representante de una casa o familia. Desde siglos a. C., este poder y título de "Señor" o representante de familia (condición que en la modernidad otorga el nombre) se reservó al varón, quien es el único auto-reconocido históricamente con capacidad de mandar y decidir sobre el patrimonio, la casa y las personas que viven en dicha casa. El filósofo Aristóteles dijo:

(...) la necesidad ha hecho aparearse a quienes no pueden existir el uno sin el otro, como son el varón y la mujer en orden a la generación (y esto no por elección deliberada, ya que en el hombre, no 
menos que en los demás animales y en las plantas, hay un deseo natural de dejar tras de sí otro ser a su semejanza). Es también de necesidad, por razones de seguridad, la unión entre los que por naturaleza deben respectivamente mandar y obedecer. (Quien por su inteligencia es capaz de previsión, es por naturaleza gobernante y por naturaleza señor, ...) (Aristóteles, 2004).

Continúa el filosofo reflexionando sobre la fórmula para acceder al título de Señor: Hesíodo estuvo en lo justo al escribir: "Lo primero de todo es la casa y la mujer y el buey labrador" (Aristóteles, 2004). En esta frase la casa representa el patrimonio, la mujer significa la procreación y el buey labrador sustituye al esclavo. Este pensamiento propio de la antigüedad, es decir, siglos antes de Cristo, de alguna manera permanece en la modernidad, muestra de ello es el artículo 60 del Código Civil del Estado de Chihuahua, relativo a la formación del nombre familiar y su registro.

La forma utilitaria de mirar a la mujer como si fuera un ser procreador pero incapaz, ha provocado el encono feminista. El enojo y la frustración de la mujer trascienden las fronteras de nuestra querida Chihuahua y también las de nuestra nación. Por eso, el pasado 8 de marzo del año 2020 se reunieron millones de mujeres en plazas, calles y construcciones emblemáticas de las ciudades de todo el mundo, para reclamar paridad entre ellas, sus hijas, madres y abuelas, con el varón. Sin embargo, percibimos que la respuesta a dicho reclamo fue la falta de empatía y el ensordecimiento colectivo.

Suele reprobarse el movimiento feminista arguyendo diversos tipos de falacias. Para empezar, se plantea la falacia del falso dilema: ¿La mujer dónde prefiere trabajar, fuera o en casa cuidando a la familia? Los detractores responden con otra falacia, la de la generalización apresurada: todas las mujeres quieren estar en casa. Una falacia recurrente es la circular, así, se asume que la cotidianidad conviene a todas y todos y, por ende, fluye sin disturbios. Cuando se habla en contra del feminismo, la falacia más usada es la Ad hóminem (ataque a la persona), la cual consiste, como su nombre lo indica, en descalificar a la persona emisora 
de un mensaje sin analizar el contenido del mismo. De aquí derivan los siguientes cuestionamientos prejuiciosos: ¿qué quieren las feminazis? ¿por qué el domingo 8 de marzo de 2020 salieron a pintar la ciudad y la glorieta de Pancho Villa en su caballo?, ¿por qué destruyen la ciudad y las obras de arte?, ¿están locas?, ¿están en sus días o son menopáusicas?, ¿cuánto les pagan? o ¿quién las manipula?

Es difícil, pero, trataré de sacudir todo prejuicio y hablar desde la experiencia, al fin, el feminismo es eso, un conjunto de experiencias concatenadas y contadas desde la vida vivida por una mujer.

\section{NATURALEZA JURÍDICA DEL NOMBRE}

El nombre es un atributo de la personalidad y un derecho (personal y colectivo), asimismo, es una institución, es decir, un conjunto de restricciones que dan forma a las interacciones humanas (Brinks, Levitsky, \& Murillo, 2019); en consecuencia, el nombre es irreductible al registro de nacimiento.

Es importante destacar que el nombre es una institución que establece relaciones de poder entre los miembros de la familia y de ellos con la sociedad. En este sentido, la Suprema Corte de Justicia en la sentencia del amparo en revisión 208/2016, del 19 de octubre de 2016, destacó: históricamente el mantenimiento o prevalencia de determinados apellidos ha pretendido perpetuar las relaciones de poder. ${ }^{5}$ En este contexto, el análisis de la figura del nombre como institución, nos permitirá realizar una propuesta con mirada feminista que favorezca las relaciones familiares y sociales equitativas.

Por otra parte, aunque las constituciones federal y la estatal no establecen claramente las distinciones entre la identidad y el nombre, por cuestión de técnica, resulta pertinente señalarlas. El derecho a la identidad y el derecho al nombre se distinguen por sus contenidos y formas, elementos y naturaleza jurídica.

5 Sentencia de 19 de octubre de 2016, primera sala, amparo en revisión, expediente 208/2016, ponente ministro Arturo Zaldívar Lelo de Larrea. 
Si bien ambas figuras se relacionan con la función de individualidad personal, no obstante, sus aproximaciones se distinguen en que la identidad comprende el contenido de la individualidad, es decir, la ideología política, educación, el género psicológico, las creencias religiosas y genética (Fernández, 1992). En cambio, el nombre se vinculan con la forma de la individualidad expresada mediante el apelativo.

El nombre comprende dos elementos: el nombre propio y el nombre familiar o apellidos, por ello, la individualidad que proporciona es de carácter formal, puesto que la persona nombrada no necesariamente tiene que estar identificada con el nombre al que responde; por ejemplo, una persona cuyo nombre propio no corresponde a su género psicológico; otro caso, la persona nombrada podría no ser quien pensó que era, es decir, hija o hijo de su padre o madre registrados, pensemos los casos de secuestro de recién nacidos en la última dictadura de Argentina. O bien, cualquier mexicana o mexicano podría no ser hija o hijo de su padre registrado y, por tanto, portar un primer apellido que genéticamente no lo individualiza. No hay que perder de vista que a diferencia de la maternidad la cual deriva de un hecho: el parto, la paternidad deriva de una presunción legal: el matrimonio y en su defecto de la declaración del varón ante el fedatario público.

Para efectos de este trabajo, la principal diferencia entre la identidad y el nombre radica en la naturaleza jurídica de estas figuras. La identidad es un derecho y surgió en Italia en 1985 (Corte de Casación Italiana, 1985), cuando el máximo tribunal italiano conoció de un caso relativo a la desnaturalización de la personalidad, en correlación con el derecho a la imagen, se pretendió responder la pregunta ¿quién soy? (Gómez, 2007). En Argentina también se oyó fuerte ¿quién soy? Así, el derecho a la identidad se erigió con el rostro de miles de niñas y niños que fueron secuestrados por el Estado durante la dictadura.

En la Constitución federal y en la del estado de Chihuahua, el derecho a la identidad se elevó al rango constitucional, 2012 - 
$2014,{ }^{6}$ y se usa para imputar la paternidad de hijos e hijas de madres solteras, es decir, para obligar a los varones que no reconocen su paternidad a la realización de la prueba en genética molecular y al cumplimiento de sus obligaciones alimentarias.

En cambio, el nombre tiene una naturaleza jurídica compleja (De Francesco, 2013), así lo describe la doctrina jurídica argentina; es decir, esta figura además de un derecho es un atributo de la personalidad y una institución, entendiendo por institución según los autores Brinks, Levitsky y la autora Murillo, las restricciones que dan forma a las interacciones humanas (Brinks, Levitsky \& Murillo, 2019).

Hechas estas acotaciones, introducimos en esta sección que el Código Civil de Alemania, de 1900, fue el primer ordenamiento jurídico que reguló el nombre de las personas como un derecho (Pliner, 1989). Salvo disposiciones aisladas ${ }^{7}$ tendientes a evitar el cambio arbitrario de nombres, a fin de salvaguardar los privilegios de la nobleza (Pliner, 1989; Pliner, 1989), la institución del nombre permaneció durante siglos en el ámbito de las costumbres y tradiciones.

Hoy, en México y Latinoamérica, ninguna autoridad cuestiona que el nombre es un derecho humano reconocido por la Constitución federal y la Convención Americana sobre Derechos Humanos y la Convención sobre los derechos del niño, cuyo alcance comprende, para efectos de este trabajo, el subregistro, el registro de nacimiento, la modificación del nombre (con y sin cambio de filiación) y lo que se distingue como la trascendencia del nombre.

6 Cabe destacar que en Italia y en Argentina el derecho a la identidad no tiene rango de derecho humano, tampoco la Convención Americana sobre Derechos Humanos consagra expresamente el derecho humano a la identidad.

7 Pliner Adolfo, p. 28. El Edicto Amboise, expedido por Enrique II de Francia en el año de 1555. Alarmado el monarca por la frecuencia con que sus súbditos, al amparo de una libertad no limitada por norma positiva alguna, cambiaban sus nombre o apellidos, abandonando los de sus familias o tomando otros nuevos conforme a sus gustos o intereses, se propuso refrenar esos abusos y prohibió toda modificación de nombre o armas salvo permiso real. Sin duda que la preocupación del legislador apunta solamente a los sujetos de la clase nobiliaria (...) 
Para efectos de este trabajo se tendrá presente que el nombre además de un derecho es una institución, pues establece y regula relaciones de poder entre los miembros de la familia y la sociedad.

\section{REGULACIÓN DEL NOMBRE DE LAS PERSONAS FÍSICAS EN CHIHUAHUA}

La normatividad que regula la institución del nombre de las personas físicas en Chihuahua corresponde al ámbito internacional, nacional y local, misma que se cita en orden jerárquico: la Constitución Política de los Estados Unidos Mexicanos (artículos 4², octavo párrafo, y 29), la Convención Americana sobre Derechos Humanos o Pacto de San José (artículo 18), ${ }^{9}$ la Convención sobre los derechos del niño de 1989 (artículos 7 y 8), ${ }^{10}$ la Ley General de los Derechos de Niñas, Niños y Adolescentes (artículo 19), ${ }^{11}$ la

8 Constitución Política de los Estados Unidos Mexicanos, Artículo 4º octavo párrafo. Toda persona tiene derecho a la identidad y a ser registrado de manera inmediata a su nacimiento. Artículo 29, segundo párrafo. (...) no podrá restringirse ni suspenderse el ejercicio de los derechos a la no discriminación, al reconocimiento de la personalidad jurídica, a la vida, a la integridad personal, a la protección a la familia, al nombre, a la nacionalidad; los derechos de la niñez;

9 Convención Americana sobre Derechos Humanos, artículo 18. Derecho al Nombre. Toda persona tiene derecho a un nombre propio y a los apellidos de sus padres o al de uno de ellos. (...)

10 Convención sobre los derechos del niño, artículo 7, numeral 1. Artículo 7, 1. El niño será inscripto inmediatamente después de su nacimiento y tendrá derecho desde que nace a un nombre, a adquirir una nacionalidad y, en la medida de lo posible, a conocer a sus padres y a ser cuidado por ellos. Artículo 8, 1. Los Estados Partes se comprometen a respetar el derecho del niño a preservar su identidad, incluidos la nacionalidad, el nombre y las relaciones familiares de conformidad con la ley sin injerencias ilícitas.

11 Ley General de los Derechos de Niñas, Niños y Adolescentes, Capítulo Tercero. Del Derecho a la Identidad, artículo 19. Niñas, niños y adolescentes, en términos de la legislación civil aplicable, desde su nacimiento, tienen derecho a: I. Contar con nombre y los apellidos que les correspondan, así como a ser inscritos en el Registro Civil respectivo de forma inmediata y gratuita, y a que se les expida en forma ágil y sin costo la primer copia certificada del acta correspondiente, (...) 
Constitución Política del Estado de Chihuahua (artículo 4, cuarto párrafo) ${ }^{12}$ y el Código Civil del Estado de Chihuahua (artículo 60). ${ }^{13}$

Es importante destacar que en el artículo 4, párrafo cuarto, la Constitución Política del Estado de Chihuahua no estipula expresamente el derecho al nombre, en este se regula el derecho a la identidad y en cierta manera el derecho al nombre, ya que se prevé la garantía del registro de nacimiento universal. Consideramos que el alcance del derecho al nombre comprende i) el subregistro ii) el registro de nacimiento (esta dimensión es la que trata la constitución estatal iii) la modificación del nombre propio y/o apellidos (en caso de reconocimiento de hijas e hijos el cambio de apellidos implica el cambio de filiación) y lo que llamamos en este trabajo iv) la trascendencia del nombre. ${ }^{14}$

Aunque en México el nombre es un derecho humano ${ }^{15}$ de gran alcance, más aún, a pesar de la importancia que significa que la nación cuente con un sistema onomástico uniforme, veraz, actualizado y ordenado, el cual sirva como instrumento para identificar a todas y a todos, es decir, niñas, niños, ciudadanas y ciudadanos, indígenas e inmigrantes, a fin de crear políticas públicas certeras

12 Constitución Política del Estado de Chihuahua, artículo 4, cuarto párrafo. Toda persona tiene derecho a la identidad. El Estado garantizará que el registro sea universal, oportuno y gratuito de acuerdo con lo establecido en la ley.

13 Código Civil del Estado, artículo 60. El nombre está constituido por el nombre propio, primero y segundo apellidos. Para la asignación del nombre propio, se observará lo siguiente: I. No podrá integrarse por más de dos sustantivos; II. No se constituirá con palabras denigrantes de la personalidad; III. No se emplearán apodos; y IV. No podrá constituirse con números. Los apellidos corresponderán por su orden, el primero del padre y al primero de la madre.

14 La trascendencia del nombre se refiere a un derecho familiar y colectivo, cuya titularidad comienza cuando muere o desaparece la persona que usa el nombre. En este sentido el autor argentino, en la obra derecho al seudónimo, pp. 29 y 30, señala: El ordenamiento de la vida humana exige, como requisito imprescindible, la identificación, segura y permanente, de los componentes de cada colectividad. Y el individuo mismo no es nada en una comunidad, si no se le da el derecho de distinguirse y diferenciarse de los demás. Todo el pasado, toda la vida presente de un pueblo está en los nombres de los que, de generación en generación, contribuyen con su vida propia e individual a la existencia colectiva.

15 El Convenio Europeo para la Protección de los Derechos Humanos y de las Libertades Fundamentales no contempla el nombre como un derecho humano o un derecho fundamental, esto no quiere decir que el derecho subjetivo al nombre no esté debidamente protegido, por el contrario, los países europeos, principalmente Alemania y Suiza están a la vanguardia en la protección y uso adecuado del nombre. 
en materia de paridad de género, seguridad pública, educación, trabajo, migración, etcétera.; indebidamente (según nuestro parecer fundado en la experiencia de las naciones vanguardistas en la materia), la regulación del nombre (la conformación del nombre, el registro de nacimiento, reconocimiento de hijas e hijos, modificación del nombre por identidad de género, error administrativo y otros), se dejó bajo la competencia de las treinta y dos entidades federativas en México; de manera queel sistema onomástico mexicano es una mescolanza de criterios que arroja datos dudosos, en especial, respecto a los grupos vulnerables (niñas, niños, indígenas, personas en situación de calle, inmigrantes y otros).

El Código Civil del Estado de Chihuahua, en el artículo 60, regula el tema relativo a la conformación del nombre. En este sentido establece,

El nombre está constituido por el nombre propio, primero y segundo apellidos. Para la asignación del nombre propio, se observará lo siguiente: I. No podrá integrarse por más de dos sustantivos; II. No se constituirá con palabras denigrantes de la personalidad; III. No se emplearán apodos; y IV. No podrá constituirse con números.

La regulación del Código Civil del Estado, así como el funcionamiento del registro civil, si bien no es un modelo de progreso, comparada con legislaciones como la de la Ciudad de México y Yucatán, hay que decirlo, sí es un ejemplo de sistematización y eficiencia.

Mediante diversas reglas establecidas en la legislación de Chihuahua se garantiza el derecho de gratuidad constitucional para obtener la primer acta de nacimiento, además, la legislación y los funcionarios que operan el registro civil, de alguna manera focalizan las finalidades principales del nombre, es decir, la individualidad y la identificación de la persona. Estas reglas facilitan que los chihuahuenses podamos registrar a nuestras hijas e hijos saliendo del hospital público o privado en el que nos asistan y de forma gratuita, así como la localización y obtención de actas de manera automatizada y expedita. 
Volviendo a las reglas para la asignación del nombre propio, la numeral I tiende a evitar la multiplicidad de nombres y pretende hacer eficiente la identificación legal y social de la persona registrada. Las numerales II, III y IV protegen la dignidad humana, evitando que la persona sea nombrada con una o más palabras que le avergüencen, humillen o no se le individualice, por ejemplo, en los campos de concentración se les llamaba a las personas usando números.

La multiplicidad de nombres dificulta la presentación social y legal de la persona. Algunos padres y madres tuvieron la costumbre de asignar a sus hijos múltiples nombres; cito a personajes destacados: el político, empresario y gobernador del estado de Chihuahua Luis Terrazas, nombrado José Luis Gonzaga Jesús Daniel Terrazas Fuentes (1829-1923); el pintor Pablo Picasso, su nombre completo fue Pablo Diego José Francisco de Paula Juan Nepomuceno María de los Remedios Cipriano de la Santísima Trinidad Ruiz y Picasso (1881-1973); el escritor argentino Jorge Luis Borges, nombrado Jorge Francisco Isidoro Luis Borges Acevedo (1899-1986); el mexicano compositor y cantante Agustín Lara: Ángel Agustín María Carlos Fausto Mariano Alfonso del Sagrado Corazón de Jesús Lara y Aguirre del Pino (1900-1970). La costumbre de asignar varios nombres tiene un origen mágico-religioso. Desde la antigüedad se ha creído que cuanto mayor sea el número de nombres de las personas, tanto mayor será la protección que le dispensen los dioses a las hijas e hijos.

La pregunta es, ¿en términos de la normatividad vigente podría nombrar a mi hija Gabriela Teresa de mi Corazón Amada Bella Elsa Leona Camila Soledad Euríale, en el Registro Civil del Estado de Chihuahua? No, no podría. El Código Civil del Estado de Chihuahua establece que el nombre propio no podrá integrarse por más de dos sustantivos.

Considero que esta disposición local no contraviene ningún artículo de la constitución federal ni de la estatal. Tampoco es inconvencional, pues no contradice la Convención americana sobre derechos humanos, menos la Convención sobre los derechos del niño. Si bien la Suprema Corte de Justicia de la Nación estableció 
que el nombre se rige por el principio de autonomía de la voluntad (SCJN, 2012), esta tesis es aislada y no tiene carácter vinculatorio.

Además, el principio de autonomía de la voluntad del nombre entra en tensión con el orden público y puede menoscabar las finalidades del derecho al nombre: la individualidad y la identificación de la persona, vulnerando así bienes de interés superior, como los derechos de las niña y niños. La facultad-obligación que ejercen madre y padre al asignar nombre a sus descendientes, por excelencia, es un derecho de la niña y el niño, por ende, el Estado tiene la obligación de garantizarlo. Sin embargo, hay entidades federativas que permiten la multiplicidad de nombres sin límite alguno, en caso de que la dificultad que llegare a tener mi hija para presentarse social y legalmente sea secundaria, podría acudir al registro civil de Chiapas, Tabasco, Guerrero, Veracruz y otras que permiten registrar a las niñas y niños con más de dos sustantivos.

En cuanto a los apellidos, el artículo 60 del Código Civil del Estado dispone: El nombre está constituido por el nombre propio, primero y segundo apellidos (...) corresponderán por su orden, el primero del padre y al primero de la madre.

Cabe destacar, esta disposición aplica en dos actos, el registro de nacimiento y la modificación del nombre con cambio de filiación, es decir, reconocimiento previsto en el artículo 74 del Código Civil del Estado.

En el artículo 60 del mismo código se asume un orden de los apellidos, primero el paterno del padre y segundo el paterno de la madre, ahí no se prevé el acuerdo de madre y padre para decidir al respecto. En el marco de la igualdad de género establecido por la legislación nacional e internacional, esta disposición ha quedado rezagada. Al respecto, el autor Víctor Simental Franco señala: la inequidad de género es un tema inacabado para el Estado Mexicano, aun cuando la Constitución Política de los Estados Unidos Mexicanos determina la igualdad entre hombre y mujer (artículo 4o), la realidad es que esta disposición en la legislación secundaria es violentada de manera constante (Simental, 2016).

Con la colonización, México replicó el sistema onomástico español, así, nuestra legislación establece que el nombre de las 
personas se integra por el nombre propio y dos apellidos paternos, primero el del padre y segundo el de la madre. Otra práctica copiada, esta muy afortunada, fue la no regulación del cambio de nombre de la mujer casada, ${ }^{16}$ evitando serios problemas de certeza jurídica y violaciones a la identidad de la mujer.

En la modernidad, existe la tendencia europea consistente en ponderar por igual la titularidad de la mujer y el varón, se prevé el acuerdo para la conformación del nombre familiar y el registro de los apellidos de las hijas e hijos, ya sea, por la elección del orden de los apellidos (sistema onomástico español) o por la elección o integración del apellido único (sistema onomástico francés); sin embargo, esta buena práctica de paridad de género no ha permeado en el Código Civil de Chihuahua.

El máximo tribunal mexicano, a diferencia de la legislación chihuahuense, prefirió seguir la tendencia europea de paridad de género y se pronunció por el acuerdo entre madre y padre para elegir el orden de los apellidos de la familia. Dicha postura fue legalizada en cuatro entidades federativas, Yucatán (2013), Estado de México (2015), Morelos (2017) y la Ciudad de México (2017), las cuales regularon que, a falta de acuerdo entre la madre y el padre, se registraría en primer lugar el apellido del padre, y en la Ciudad de México, el juez u oficial del registro civil dispondrá el orden de los apellidos.

En el estado de Jalisco, en el año 2020, se presentó una iniciativa para que la madre y el padre puedan decidir el orden de los apellidos y si no hubiera acuerdo, el oficial del registro civil resolverá haciendo un sorteo (Expansión Política, 2020). De esta iniciativa es rescatable el cuestionamiento siguiente: cuando se registra el nacimiento de un recién nacido y no haya acuerdo de los progenitores respecto al orden de los apellidos ¿cuáles son los

16 Los sistemas que replican el sistema onomástico francés como Estados Unidos, Alemania, Argentina y otros, regulan el cambio de apellido de la mujer casada, generando serios problemas de seguridad jurídica y violaciones a la identidad de la mujer; un caso muy conocido es el de la canciller federal de Alemania, Angela Merkel, cuyo apellido es el del primer marido con quien estuvo casada cinco años (1977 a 1982); sin embargo, una vez divorciada, no pudo cambiarlo por el propio "Kasner" o por el de su marido "Sauer", pues, ella ya tenía una carrera política consolidada y era reconocida en Alemania y en el mundo como Angela Merkel. 
parámetros o cómo el juez u oficial del registro civil determinará cuál apellido va primero? Arbitrariamente, o bien, por sorteo, lo propuso una legisladora jalisciense. Al respecto, los suecos ${ }^{17}$ anteponen su pragmatismo y resuelven lo siguiente: Los niños suecos llevan los apellidos según el orden que los padres elijan, pero si la pareja no llega a un acuerdo, el niño queda registrado con el apellido de su madre (Europa Press, 2017).

El camino en Chihuahua, para lograr la participación de la mujer en la formación del nombre familiar, será largo y aún no comienza; sin embargo, apostamos a que un día la transformación sucederá. Para entonces, hay que enumerar los argumentos que son de índole: i) legal, ii) biológicos y iii) sociales, con base en los cuales madre y padre deberán acordar el orden de los apellidos de sus hijas e hijos y en caso de que no haya acuerdo, será a la madre a quien corresponda la elección. A continuación, se explican los argumentos relacionados para esta propuesta:

\section{i) Argumentos legales}

La ley se basa en el hecho natural del parto y en una presunción jurídica -el matrimonio-, o en su defecto, la manifestación del varón ante la autoridad competente, para establecer los vínculos filiales. ${ }^{18}$ La maternidad puesto que deriva del parto, a diferencia de la paternidad que se presume, es un hecho no una ficción jurídica. Al respecto, el artículo 62 del Código Civil de Estado señala en el segundo párrafo que:

Para que se haga constar en el acta de nacimiento, el nombre del padre de un hijo nacido fuera del matrimonio, es necesario que aquél lo pida por sí o por apoderado especial (...) La madre no tiene derecho a dejar de reconocer a su hijo. Tiene obligación de que su nombre figure en el acta de nacimiento de su hijo. (...)

17 Los pueblos escandinavos tenían una extensión limitada del linaje, de padre a hijo o hija, el cual se perdía entre abuelos y nietos, así se formaron los apellidos con el nombre del padre agregando los sufijos son o dóttir, por ejemplo: Leíf Erikson (hijo de Erik), Freydís Eiríksdóttir (hija de Erik).

18 El Código Civil del Estado no regula la maternidad subrogada, solamente se prevé el hecho de que es madre la que pare. 
Este artículo recoge implícitamente la condición natural del parto como base para establecer las relaciones filiales, pero, además nos muestra un tratamiento desigual entre la mujer y el varón con relación a los hijos e hijas. Mientras que la mujer no tiene derecho a dejar de reconocer a la niña o niño que parió, el padre que no está casado con la madre, tiene que comparecer ante el oficial del registro civil a pedir que la o el niño se registre como suyo. Esta disposición es una de las causas por las que el reconocimiento de hijos e hijas de madre soltera, se entiende por la sociedad y autoridades como una concesión graciosa por parte del varón, quien acude por su propio derecho, en vez de obligación, al Registro a manifestar su paternidad.

El prejuicio en contra de la madre soltera no es exclusivo de Chihuahua o de México; se citará un caso chileno para ejemplificar que el acto de reconocimiento de hijos de madre soltera, se mal entiende como un favor que se le hace al niño, la niña y la madre soltera. El 29 de septiembre de 2016, se denunció que, en la Ciudad de Pozo Almonte, en la Provincia del Tamarugal, Chile, un extranjero desconocido reconoció a una niña como su hija, situación que descubrió la madre de la menor luego de solicitar un certificado de nacimiento que daba cuenta del hecho. Al respecto, la directora regional del Registro Civil manifestó: "La irregularidad no es tan fácil de resolver, puesto que el acto de reconocimiento de un hijo es irrevocable" (Almonte, 2016).

En el Registro Civil del Estado de Chihuahua, los únicos requisitos sustanciales para modificar el nombre, la filiación y la patria potestad de la hija o el hijo menor de una madre soltera son: 1) que el acta de nacimiento del menor no tenga padre registrado y 2) las voluntades de la madre y de quien se presente ante el Registro Civil como el padre. Lo anterior es contrario a los derechos de las niñas y niños y, por analogía, a la jurisprudencia que establece el derecho de los menores a participar en los procedimientos jurisdiccionales que afectan su esfera jurídica (SCJN, 2017).

Hay que destacar, los derechos de las niñas, niños y adolescentes comprenden un interés jurídico o bien superior, es decir, muy por encima de los derechos y obligaciones derivadas de las 
figuras de maternidad, paternidad, patria potestad, maternidad subrogada y donador genético, están los derechos de la niñez. El derecho humano de alimentos de las niñas y niños debe garantizarse siempre, por ello, son sujetos deudores de este derecho: en primer lugar, madre y padre, segundo lugar, el gobierno, la familia, las y los ciudadanos, en otras palabras, todas y todos somos sujetos deudores del derecho a alimentos de la infancia mexicana.

Entonces, por qué el artículo 62 del Código Civil del Estado no prevé, en pro del interés superior del menor, se registre la paternidad del recién nacido o nacida, previa declaración de la madre soltera ante el oficial del registro civil, confirmada con la prueba genética respectiva. La ley no prevé este supuesto, porque la mujer y el varón no son iguales ante ella. Si el varón incumple la obligación de comparecer ante el Registro Civil a declarar su paternidad, la madre soltera tendrá que registrar al menor como hija o hijo sin padre y posteriormente iniciar un costoso, largo y tortuoso juicio jurisdiccional para corretear al varón e imputarle una paternidad que no deseaba. Más aún, cuando el juicio de paternidad se gane, el nombre y la filiación de la hija o hijo se modificará, situando el apellido paterno del padre en primer lugar, seguido del apellido paterno de la madre, en segundo lugar; en efecto, la ley protege el derecho del varón para establecer su estirpe. Por lo tanto, en este trabajo se propone la modificación de los artículos 60 y 74 del Código Civil del Estado, en los términos que se señalan más adelante.

\section{ii) En términos biológicos}

El aparato reproductivo femenino y la condición de mamíferos, obliga a la especie humana a formar relaciones de vida y procreación desiguales entre mujer y varón con relación a los críos. La perpetuación de la humanidad como especie de mamíferos requiere, primero, que la mujer cargue en su vientre al crío, después, que lo amamante, independientemente que, en una visión futurista, ambas funciones puedan llegar a sustituirse artificialmente. 
Lo cierto es que la maternidad deriva de un hecho natural y biológico: el parto, a diferencia de la paternidad, la cual se determina mediante una construcción jurídica: el matrimonio y en su defecto la manifestación del varón ante el fedatario público.

La propuesta feminista consistente en que la mujer participe en la integración del nombre familiar, acordando con el varón el orden de los apellidos de la hija o hijo de ambos y en caso de que no haya acuerdo sea la mujer quien decida, da certeza jurídica a la persona, la familia y la sociedad e identidad sólida a la niña o niño registrado.

La idea de ponderar el linaje del varón sobre los hechos, las ciencias naturales y los derechos de la mujer, es una arrogancia y una construcción muy endeble del patriarcado hegemónico, la cual va a caer, es decir, se derrumbará con la realidad a cuestas, pues la mujer es la que engendra, pare y da certeza a las relaciones familiares.

\section{iii) Argumentos sociales}

Dada mi formación de abogada positivista-analítica, creo que este tipo de argumentos salen del espacio donde me siento cómoda, sin embargo, deben abordarse para fortalecer la propuesta feminista que sostengo. Al fin, lo mencionamos, el feminismo es eso, las experiencias vividas y contadas por una mujer.

En principio, hay que distinguir el plano del deber del plano del ser. En el ámbito del deber, irrefutablemente, todas y todos somos deudores solidarios de los derechos de la niñez mexicana, en primer lugar, madre y padre por igual, en segundo lugar, gobierno, ciudadanas y ciudadanos y la comunidad en general. Asimismo, los derechos de los niños representan un bien superior y prioritario sobre cualquier otro tipo de derecho u obligación, lámese maternidad, paternidad, patria potestad, maternidad subrogada y donador genético. El interés superior del niño se fundamenta en el artículo $4^{\circ}$, noveno párrafo, de la Constitución Política de los Estados Unidos Mexicanos, la Convención sobre los derechos del niño, la Ley General de los Derechos de Niñas, Niños y Adolescentes, y el artículo $4^{\circ}$ de la Constitución Política del Estado de Chihuahua. 
En el mismo sentido, la tesis aislada Guarda y custodia. El artículo 282, apartado b, fracción ii, tercer párrafo, del Código Civil para el Distrito Federal (hoy Ciudad de México), que la concede ex ante a la madre, es violatorio del principio de igualdad y no discriminación, emitida por la Suprema Corte de Justicia de la Nación (2020) señala que:

(...) las normas generales que establecen distinciones basadas en las categorías sospechosas enunciadas expresamente en el artículo 10. de la Constitución Federal -entre las que se encuentra el género-, no admiten este tipo de interpretación, antes bien, las mismas deben ser sometidas a un escrutinio estricto. Ello, debido a que la disposición en cita genera una distinción normativa en función del género y no cumple con los estándares del test de igualdad a la luz de un escrutinio estricto; en tanto no es una medida idónea para satisfacer de una mejor forma el interés superior del menor, pues establece una presunción ex ante en favor de la madre sin evaluar cuál sería la situación más benéfica para el infante, por lo que, lejos de potencializar este principio, lo contraviene al impedir que el juzgador cumpla con su obligación de evaluar tanto las condiciones fácticas que generan la controversia, ya sean las características y posibilidades de los progenitores, como la opinión del menor y su relación con estos. Así, el establecimiento de una regla absoluta sin la admisión de excepciones encaminadas a buscar un mayor beneficio para el infante, ignora la pluralidad de la realidad social. Ello, aunado a que la preferencia materna y el presumir que los hijos deben quedar al cuidado y responsabilidad de las madres por presunción legal, no solo reafirma estereotipos de género tradicionales, sino profundiza el mandato y la correspondiente culpa o doble carga de responsabilidad que se genera fundado en el binomio de mujer-madre.

Esta tesis corrobora que las facultades derivadas de la maternidad, no pueden ponderarse por encima o igual a los derechos de la niña o niño; en palabras de la civilista argentina Grosman, nos parece conveniente introducir estas reformas: Reemplazar en el articulado legal la denominación "patria potestad" por "responsa- 
bilidad parental", y la voz "tenencia" por "régimen de convivencia con el hijo” (Grosman, 1998), ello para una mejor protección del interés del menor. El término patria potestad da la pauta para ejercer la maternidad y la paternidad en forma de poder respecto a la niña o niño y no de responsabilidad, situación descrita en la tesis en cuestión.

Asimismo, el precedente en cuestión combate la presunción de que las hijas e hijos deben quedar al cuidado y responsabilidad de las madres, situación que reafirma estereotipos de género tradicionales y profundiza el binomio de mujer-madre. En efecto, en este trabajo se ha mencionado que todas y todos somos deudores solidarios del cumplimiento de los derechos de la niñez, en primer lugar, madre y padre en igualdad, segundo lugar, gobierno y comunidad. Lamentablemente, la realidad de la infancia chihuahuense y mexicana dista del plano del deber ser; los derechos de las niñas, niños y adolescentes se vulneran a diario, en escuelas, iglesia, en la familia y en la calle.

Por otra parte están, en el plano del ser sumidos en la cotidianidad, lejos de las leyes, los derechos fundamentales y los juicios contenciosos entre madre y padre que pelean a muerte por un poder sobre la niña o el niño; lo cierto es que en el plano del ser, en el fáctico, la mujer sea hija, hermana, madre, tía o abuela, constituye la piedra angular sobre la cual se construye la identidad de la niñez mexicana. Lo veo en cada junta escolar, preescolar y primaria, por cada dieciocho mujeres, aproximadamente, asiste un varón; y en los grupos informativos de las redes sociales, donde escriben incansablemente, la mayoría somos mujeres, algunas madres, otras abuelas, tías, hermanas, novias del papá, aún así, siempre somos "los padres de familia". A las mujeres nos dicen "papis" y rinde cuentas "la sociedad de padres de familia", es decir, en títulos nominativos e institucionales no existe el binomio de mujer-madre, referido en la tesis aislada citada con antelación. En las escuelas públicas y privadas del estado de Chihuahua donde estudian nuestras hijas e hijos, se genera el extraño binomio de mujer-padre, somos algo así como "Las padres de la familia de nuestro marido" o las invisibles. 
Ahora bien, salgamos del ámbito formal para hablar de la no escrita sabiduría del pueblo chihuahuense. Habrás escuchado alguna vez un dicho de las abuelitas que dice: "Los hijos de mis hijas mis nietos serán, los hijos de mis hijos... en duda estarán”. Este obedece a dos causas, la primera es de índole natural, la cual trasciende al ámbito jurídico y da certeza jurídica a las relaciones familiares (ver los artículos 55 y 62 del Código Civil del Estado que regulan el parto como origen de la maternidad). Reiteramos, con excepción de la maternidad subrogada, es un hecho, la madre de una niña o niño será quien lo parió. En cambio, el padre de una niña o niño se determinará con base en una presunción legal, el matrimonio, y, en su defecto, la declaración del varón ante el fedatario público; por eso, la ley, el gobierno y la familia no tienen más opción que presumir la supuesta paternidad, ya que nadie, ni siquiera la madre y el padre conocen exactamente el momento de la concepción (por eso, algunas abuelitas dudan de ser la verdadera abuela de las hijas e hijos de su hijo). La segunda causa es de índole social, aunque exista una relación consanguínea entre el crío y el padre y a su vez con la familia de este; en la realidad, la mujer con sus decisiones, hábitos, roles y trabajo, es quien condiciona la formación y educación de los niños y niñas chihuahuenses.

En conclusión, estos fueron los argumentos legales, biológicos y sociales que consideramos para proponer la siguiente redacción al artículo 60 del Código Civil del Estado:

(...) La prelación de los apellidos, será la que los progenitores convengan y en caso de no existir acuerdo, corresponderá a la madre esa decisión. El orden de apellidos registrado para el primer hijo o hija se empleará para los demás hijos e hijas del mismo vínculo.

En cuanto a la modificación del nombre con cambio de filiación, se propone la siguiente redacción al artículo 74 del Código Civil del Estado:

Si el reconocimiento se hiciere después de haber sido registrado el nacimiento, el nombre propio y el apellido primero de la persona 
registrada se mantendrán sin modificación, el apellido segundo se cambiará por el del progenitor que reconozca al hijo o hija. (...)

\section{LA PRAXIS: JURISPRUDENCIA Y EL REGISTRO CIVIL DEL ESTADO DE CHIHUAHUA}

Se presume que el nombre de las personas surgió al mismo tiempo que el lenguaje y con las primeras formas de civilización (Pliner, 1989). Durante milenios el nombre existió ligado al ámbito consuetudinario. El código alemán de 1900 fue el primer instrumento jurídico que consideró el nombre como un derecho (Pliner, 1989). La integración del nombre compuesto por el nombre propio y apellidos o nombre familiar es relativamente moderna. Con excepción de los romanos, los pobladores de la antigüedad, hebreos, griegos, árabes, chinos, japoneses, hindúes y germanos, solo tenían el nombre principal y no existían los apellidos (Pliner, 1989), estos surgieron con la evolución y complejidad de las sociedades modernas y con la necesidad del patriarcado de establecer un linaje.

La invención del apellido como elemento del nombre que trasciende de generación en generación, se atribuye a la finalidad de identificación de la persona. Hablo de la identificación en términos de igualdad y pertenencia, es decir, individuos separados se unen por medio de los lazos de sangre y solidaridad, para integrar linajes, familias, comunidades y naciones, por medio de los apellidos.

Siendo el nombre una institución que emergió y se desarrolló durante siglos en el ámbito consuetudinario, puede entenderse que la praxis vaya un paso adelante de la norma jurídica. En diciembre de 2017, se publicó la sentencia de la Suprema Corte de Justica por la cual se determinó que privilegiar el apellido paterno del hombre sobre el de la mujer refuerza prácticas discriminatorias en contra de la mujer. El caso derivó de la petición formulada por ciertos progenitores, dirigida al Registro Civil de la Ciudad de México, para que al registrar a sus hijas se invirtiera el orden de los apellidos que entonces se establecía en el reformado artículo 
58 del Código Civil para el Distrito Federal. En amparo en revisión 208/2016, el máximo tribunal mexicano dispuso:

El sistema de nombres es una institución mediante la cual se denomina y da identidad a los miembros de un grupo familiar. Este, a su vez, cumple dos propósitos. Primero, sirve para dar seguridad jurídica a las relaciones familiares, fin que por sí solo podría considerarse constitucionalmente válido. No obstante, el sistema de nombres actualmente vigente también reitera una tradición que tiene como fundamento una práctica discriminatoria, en la que se concebía a la mujer como un integrante de la familia del varón, pues era este quien conservaba la propiedad y el apellido de la familia. En razón de lo anterior, la imposibilidad de anteponer el apellido materno atenta contra el derecho a la igualdad y no discriminación de estas debido a que implica reiterar la concepción de la mujer como miembro secundario de una familia encabezada por el hombre. ${ }^{19}$

En Chihuahua y en la práctica, a qué pareja podría interesarle solicitar el registro de nacimiento de su hija o hijo, con la prelación de los apellidos de manera distinta a como se dispone legalmente; si bien, esta práctica no debe ser solo para quienes deseen preservar una estirpe, es difícil para la madre y el padre concebir una forma de interacción familiar diferente a la establecida en el Código Civil del Estado, la cual prevalece de manera tradicional, es decir, la familia actúa, se presenta y conoce con el nombre familiar del señor de la casa. Cabe destacar, que ante una negativa por parte del Registro Civil para modificar el orden de los apellidos de la hija o hijo registrado, será necesario promover un juicio de amparo, el cual es costoso, tardado y no hay garantía de la obtención de la prestación.

Los primeros pasos para asegurar la participación de la mujer en la formación del nombre familiar pueden ser desalentadores, de aquí la importancia de trabajos y divulgaciones como esta. Las prácticas de discriminación hacia la mujer pueden empezar a ser

19 Tesis 1a. CCIX/2017 (10a.), Semanario Judicial de la Federación, Décima Época, tomo I, diciembre de 2017, p. 434. 
advertidas y cuestionadas para transformarlas en normatividad, actos y hechos que mejoren la convivencia y garanticen los derechos de todas y todos.

Será importante que las y los operadores del registro civil estén actualizados y sensibles respecto a la noción de paridad de género, para que cuando reciban la solicitud de cambio del orden de los apellidos, con fundamento en el derecho humano a la igualdad de género establecida en el artículo 40 constitucional y convenios internacionales de la materia, la acepten sin necesidad de acudir a tribunales, puesto que todas las autoridades tienen la obligación de promover, respetar, proteger y garantizar los derechos humanos en términos del artículo 10 constitucional. El movimiento transformador feminista parece surgir de la calle, pasará por el registro civil y llegará al derecho.

Todas y todos habremos de erradicar el prejuicio de que los que se apellidan como la mamá son hijas o hijos de madres solteras. Esta discriminación ha vulnerado no solo los derechos de la mujer, sino también los derechos e inclusive la integridad de las niñas y niños. Sumergidos en el prejuicio, se aprecia como una concesión graciosa o un favor el reconocimiento que el hombre hace para el hijo o hija de la mujer soltera.

\section{PROMOCIÓN, RESPETO, PROTECCIÓN Y GARANTÍA DEL DERECHO HUMANO AL NOMBRE}

El nombre, además de un atributo de la personalidad y una institución, es un derecho humano, de conformidad con el artículo 29 de la Constitución Política de los Estados Unidos Mexicanos y el artículo 18 de la Convención Americana sobre Derechos Humanos. La primera en el articulo 10, párrafo tercero, establece que todas las autoridades, en el ámbito de sus competencias, tienen la obligación de promover, respetar, proteger y garantizar los derechos humanos.

Las autoras argentinas Graciela Medina y Gabriela Yuba distinguen estas cuatro obligaciones de los Estados respecto a los derechos humanos: la obligación de promover el derecho en cues- 
tión, se refiere al deber de desarrollar condiciones para que los titulares del derecho accedan al bien; la obligación de respetar implica la obligación del Estado de no obstaculizar o impedir el acceso, el goce de los bienes que constituyen el objeto del derecho; la obligación de proteger, relacionada con el deber de impedir que terceros interfieran el acceso a esos derechos; la obligación de asegurar o garantizar, en términos de la constitución federal mexicana, implica asegurar que el titular del derecho acceda al bien (Medina \& Yuba, 2013).

La obligación de promover el derecho al nombre en Chihuahua, se atribuye al Congreso del Estado, consiste en impulsar la reforma de los artículos 60 y 74 del Código Civil del Estado de Chihuahua, en los términos planteados en este trabajo, a fin de que existan las condiciones legales para que la mujer intervenga en la conformación del nombre familiar, en los actos del registro de nacimiento y especialmente en el de reconocimiento de hijas o hijos.

La obligación de respetar el derecho al nombre en Chihuahua se atribuye a las autoridades del Registro Civil, con el objeto de que acepten las peticiones de los progenitores para registrar a sus hijas e hijos, con la prelación de apellidos que ellos convengan, sin la necesidad de acudir a tribunales federal por la violación del derecho a la igualdad de género (artículo $4^{\circ}$ constitucional) y el derecho al nombre (artículo 18 de la Convención Americana sobre derechos humanos).

La obligación de proteger el derecho al nombre es atribuible a todas y a todos, especialmente para las madres de las niñas y niños registrados o reconocidos, así como para las autoridades del registro civil que llevan a cabo el registro de actas; esta obligación implica erradicar los prejuicios propios y de terceros que impiden a la mujer acceder a la titularidad de las responsabilidades y los derechos que el nombre representa.

En cuanto a la garantía del derecho al nombre, todas las autoridades de Chihuahua del orden estatal y municipal, correspondientes a los poderes legislativo, ejecutivo y judicial, están obligadas a que la universalidad del derecho al nombre incluya a 
la mujer, niñas, niños y a la familia chihuahuense, conjugando el cumplimiento de las obligaciones mencionadas.

\section{PROPUESTA FEMINISTA PARA PROMOVER EL DERECHO AL NOMBRE EN CHIHUAHUA}

Para enmarcar la propuesta feminista del derecho al nombre en Chihuahua, viene a cuenta un texto de la investigadora Susana Thalía Pedroza de la Llave, en colaboración con el investigador Rodrigo Gutiérrez, dicen así: "es muy distinto proteger a un individuo, que proteger los derechos de ese individuo". En el primer caso, el sujeto no es considerado como sujeto de derechos, sino al que hay que proteger, y no se debe olvidar que ha sido en nombre del cuidado y la protección que a lo largo de la historia se han cometido enormes atropellos (Pedroza \& Gutiérrez, 2001).

De aquí se advierte la importancia de proteger los derechos de la mujer, no propiamente a la mujer, como si ella fuera un ser procreador y frágil, por ende incapaz de representar a su familia y sobrevivir sin el amparo y protección del varón proveedor, pues, según el filósofo Aristóteles (2004), el hombre es quien cuenta con capacidad para proveer, mandar y decidir sobre la casa y los que viven en ella. Asumir que una persona carece de capacidad para tomar decisiones y asumir las consecuencias, es fuente de discriminación de cualquier tipo.

Las relaciones familiares respetuosas se presentan en un ambiente de paridad de género y requieren mirar a la mujer precisamente como se mira al varón, como un sujeto titular de derechos y obligaciones, con capacidad para contraer y afrontar las responsabilidades propias y familiares, así como personales y patrimoniales.

Es injusto que la ley y la sociedad nieguen a la mujer participar en la conformación del nombre familiar, relegándola a un lugar secundario en el orden de los apellidos. Paradójicamente, es la mujer quien, por una parte, desempeña un rol prioritario en la familia, asumiendo (de facto y no legalmente) la gran responsabilidad del cuidado de los integrantes más vulnerables de la familia, niñas, niños, adolescentes, personas con discapacidad y adultos 
mayores; por la otra, la maternidad se establece de un hecho cuasi irrefutable: el parto. Este acontecimiento natural da seguridad y certeza jurídica a las relaciones familiares; a diferencia de la paternidad cuyo origen es una presunción legal o una manifestación que a veces se niega y es necesario un juicio jurisdiccional para imputarla.

La metáfora del autor argentino Juan M. Semon que dice: “(...) Una persona sin nombre es como una obra literaria o científica sin título ni referencias de su autor. Es un ser viviente, sin derechos y sin responsabilidad individual por sus actos" (Semon, 1946), nos hace pensar que una manera de gozar de las libertades e igualdades que implica la paridad de género, es mediante la asunción de las responsabilidades legales y sociales que derivan del nombre.

Así, la propuesta de este trabajo se resume a lo siguiente: por lo que hace al registro de nacimiento, se planteó regular en el Código Civil del Estado de Chihuahua, el acuerdo de la pareja respecto a la prelación de los apellidos de las hijas e hijos, a falta de este, la decisión será tomada por la madre. En cuanto a la modificación de nombre con cambio de filiación o acto de reconocimiento, se propuso la no alteración del nombre propio, ni la del primer apellido, incluyendo, en todo caso, como segundo apellido el del progenitor que reconoce a la niña o niño previamente registrado.

Esta es una propuesta sencilla, pero de gran impacto. La forma de interacción que la institución del nombre establece entre el varón, la mujer y los hijos e hijas, la sociedad y el gobierno, puede repensarse para dejar de reproducir prototipos inadvertidos que datan desde la antigüedad, cuando el centro de la civilización era el hombre, llamado entonces Pater Familias y después Señor feudal. En la actualidad esta practica discriminatoria permanece, negando a la mujer el derecho de participar en la formación del nombre familiar, como sabemos, cuando se registra al niño o niña se le asigna un nombre propio seguido de dos apellidos, el paterno del padre y el paterno de la madre; o bien, la mujer casada, como práctica social, une a sus apellidos los del marido o utiliza el genitivo “de", simbolizando pertenencia al cónyuge. 
El nombre y su uso es una herramienta esencial para materializar derechos y responsabilidades atribuibles a un titular, por eso la importancia de promover la intervención de la mujer en la conformación del nombre familiar, ya que esta es una manera de visibilizarla y crear nuevas y equitativas formas de interacción en la familia y en la sociedad, la principal, entre la madre y los hijos e hijas.

La portación del primer apellido igual al de la madre, nunca más debe representar el hijo o hija de la madre soltera, sino el hijo o hija de la madre con capacidad legal y social para representar a su familia, siendo titular de derechos y responsabilidades ante cualquier instancia. ¡Vaya!, la noción que se propone es muy diferente al prototipo de la madre cuidadora, quien ama, alimenta y limpia a la familia que pertenece a un supuesto Señor de la Casa.

Por último, a propósito de la responsabilidad y paridad de género, resulta oportuno citar el pensamiento del defensor de derechos humanos Nelson Mandela, en torno a un sueño de libertad:

\section{Libertad de ser responsables}

He pasado por el largo camino a la libertad.

He tratado de no flaquear, pero me he tropezado en el camino. He descubierto un secreto: después de escalar una alta montaña descubres que aún te faltan muchas otras por subir.

He decidido descansar aquí un momento, pero sé que solo puedo descansar un rato porque ser libre significa tener responsabilidad y no pienso detenerme:

mi camino aún no acaba.

Nelson Mandela (Mandela, 2015)

\section{REFERENCIAS}

Conapred (Consejo Nacional para Prevenir la Discriminación) (2007). 73670 Testimonio de un sobreviviente de los campos de exterminio nazis. Colección testimonios sobre discriminación. México: L. Díaz, Ed. 
Corte de Casación Italiana, C. V. (1985). Sentencia caso Veronesi. Luces Gil, F. (1978). El nombre civil de las personas naturales en el ordenamiento jurídico español. Barcelona: Bosch Casa Editorial S.A.

Expansión política (14 de febrero de 2020). En Jalisco, proponen sorteos para decidir el orden de los apellidos de los hijos. Obtenido de https://politica.expansion.mx/estados/2020/02/14/enjalisco-proponen-sorteos-para-decidir-el-orden-de-los-apellidosde-los-hijos.

ADN Nacional (31 de diciembre de 2016). Niña fue reconocida como hija por un extranjero desconocido en Pozo Almonte. Obtenido de https://www.adnradio.cl/nacional/2016/12/31/ nina-fue-reconocida-como-hija-por-un-extranjero-desconocidoen-pozo-almonte-3344966.html

Aristóteles (2004). Ética Nicomaquea. Colección "Sepan cuantos...", núm. 70, Ciudad de México: Porrúa.

Brinks, D. M., Levitsky, S., \& Murillo, M. V. (2019). Understanding Institutional Weakness. New York: Cambridge University Press.

De Francesco, F. (2013). "El nombre de las personas físicas, concepto, evolución histórica. Naturaleza Jurídica, teorias". En K. A. Bigliardi, Aspectos constitucionales y civiles del nombre Buenos Aires: De los cuatro vientos, p. 37.

Europapress (30 de junio de 2017). ¿El de la madre o el del padre? Así se decide qué apellido va primero en otros países. Obtenido de https://www.europapress.es/sociedad/noticia-madre-padreasi-decide-apellido-va-primero-otros-paises-20170531134006. html.

Fernández Sessarego, C. (1992). Derecho a la identidad personal. Buenos Aires: Astrea.

Grosman, C. P. (1998). El interés superior del niño,. En C. P. Grosman. Los derechos del niño en la familia. Discurso y realidad. Buenos Aires: Editorial Universidad.

Gómez Bengoechea, B. (2007). Derecho a la identidad y filiación: búsqueda de orígenes en adopción internacional y en otros supuestos de filiación transfronteriza. Madrid: Dykinson. 
Mandela, N. (2015). Libertad de ser responsable. En A. I. Section, Sueños de libertad en palabras e imágenes (pág. s/n). Cd. de México: D.R. SM de ediciones S.A. de C.V.

Medina, G., \& Yuba, G. (2013). Ley de Registro Nacional de Datos Genéticos vinculado a delitos contra la integridad sexual. Antecedentes. Derecho comparado. Derecho de familia y de las personas(8), pp. 175-186.

Pliner, A. (1989). El nombre de las personas: legislación, doctrina, jurisprudencia, derecho comparado. Buenos Aires: Astrea.

Pedroza de la Llave, S. T., \& Gutiérrez Rivas, R. (2001). Los niños y niñas como grupo vulnerable: una perspectiva constitucional. En D. Valadés, \& Gutiérrez Rivas Rodrigo (Coords.). Derechos Humanos Memoria IV Congreso Nacional de Derecho Constitucional. México,: Universidad Nacional Autónoma de México, Instituto de Investigaciones Jurídicas.

Semon, J. M. (1946). El derecho al seudónimo. Buenos Aires: tipografica Editora.

SCJN (Suprema Corte de Justicia de la Nación) (17 de marzo de 2017). Derecho de los menores de edad a participar en los procedimientos jurisdiccionales que afecten su esfera jurídica. Lineamientos para su ejercicio, Tesis: 1a./J.12/2017 (10a.).

SCJN (Suprema Corte de Justicia de la Nación) (18 de enero de 2012). Derecho humano al nombre. Su sentido y alcance a partir de la Constitución Política de los Estados Unidos Mexicanos y a la luz de los tratados internacionales, Tesis: 1a. XXV/2012 (10a.).

SCJN (Suprema Corte de Justicia de la Nación) (14 de agosto de 2020). Guarda y Custodia. El Artículo 282, Apartado B, Fracción Ii, Tercer Párrafo, del Código Civil para el Distrito Federal (Hoy Ciudad de México), Que la concede ex ante a la madre, es violatorio del principio de igualdad y no discriminación., Tesis: 1a. XV/2020 (10a.).

SCJN (Suprema Corte de Justicia de la Nación) (16 de agosto de 1985). Mujer Casada, nombre de la... 248459.

SCJN (Suprema Corte de Justicia de la Nación) (4 de mayo de 2012). Nombre de casada. Constituye una práctica social que 
no puede llevar a desconocer la identidad de la mujer., Tesis: I.3o.C.15 C (10a.).

Simental Franco, V. A. (2016). Inconstitucionalidad del apellido paterno en la integración del nombre,. Foro jurídico (159), pp. 33-35. 